\title{
Aligning Linguistic and Brain Views on Language Comprehension
}

\author{
Kara D. Federmeier, Robert Kluender, and Marta Kutas
}

\section{INTRODUCTION}

Language affords human beings an incredible degree of representational flexibility within the limits of highly restrictive constraints. For example, despite the remarkable ability of the human vocal tract to produce all kinds of sounds, only a limited subset of these is actually used in the world's languages. A native speaker of any of the world's languages will have an intuitive sense for what kinds of sounds can and cannot (e.g., coughs and raspberry noises) figure as possible sounds in a human language, even if none of the sounds in question occurs in his or her own particular language. Individual languages exhibit an even more restricted inventory of speech sounds, the lowest attested number being eleven. However, this small repertoire of sounds is grouped and ordered to create a very much larger set of words in a language, termed its lexicon. Likewise, the entries in this lexicon, although large in number-typically consisting of many thousands of entries-can be combined to form literally an infinite number of sentences describing real, imaginary, and impossible objects and events, not to mention emotional states and abstract concepts.
Especially striking is that almost all humans learn this complicated coding system early in life and use it throughout their life span with ease. Every day, humans produce and comprehend completely new strings of words, at a rate of about 150 words per minute (Maclay and Osgood, 1959). No other species is capable of this tremendous versatility, either naturally in the wild or when trained in humanlike communication systems for experimental purposes in the laboratory. Our linguistic ability is one of the many salient characteristics that distinguish humans from other species. Another is the relative size and complexity of our brains, and surely these two features are not unrelated or logically independent. In fact, we can say that the degree of flexibility and efficiency we exhibit in this cognitive domain is a consequence of the structure of language, together with the structure of the entity that represents it and mediates its processing, the human brain. In this chapter we examine how these come together in neural imaging studies of language comprehension relying on physiological measures, with an emphasis on electrical brain activity (an equally compelling story could be told for language production, but that tale will not be told here). 


\section{LANGUAGE STRUCTURE: THE LINGUIST'S VIEW AND THE BRAIN'S VIEW}

The language system is structured at multiple levels, ranging from its physical form to its referential meaning in context. Phonetics and phonology are the study of language sounds. Phonetics describes how the speech sounds utilized by all human languages are produced, transmitted, and perceived. Within any given language, sounds (and hand shapes in signed languages) come to be systematically organized and categorized (into "phonemes"). For example, various combinations of different actual sound patterns (mediated by measurably different vocal tract configurations) may all yield something that an English speaker interprets as a " $\mathrm{t}$ " - the (different) sounds in the words "top," "stop," "pot," and "button," for example. Phonology is the study of such sound systems and the kind of knowledge that people have about the sound patterns of their particular language.

"Morphemes" are combinations of phonemes that have come to have their own meaning. Some are whole words (e.g., "cat"), whereas others are affixes that modulate the meaning of whole words (e.g., the /s/, which, when added to the end of an English word, makes that word plural). Morphology, then, is the study of the patterns that govern word formation, including both how morphemes combine to yield new meanings or parts of speech (derivational morphology), and how they combine to create different forms of the same word (inflectional morphology). Just as morphemes are combined to create new words and new forms of words, whole words are combined to make larger units of language-phrases, clauses, sentences, and discourses. Within and across languages, the way in which certain words and types of words come to be put together to create these larger language units is patterned. Phrases, for example, are built around particular types of words. Noun phrases may contain several different types of words but must contain at least one noun and must not contain a verb. Phrases act as units that can be found in multiple places in a sentence-for instance, noun phrases may be subjects, objects, or parts of prepositional phrases. The study of language grammars - of how words (and affixes) pattern across phrases, sentences and discourses-is known as syntax.

Ultimately, humans use language to transmit information-meaning-that depends not just on the general pattern of sounds or words, but on the specific words used, their specific pattern, and the specific context (linguistic, social, environmental) in which they occur. The study of language meaning in general, known as semantics, and of meaning in its larger context, known as pragmatics, asks how language is used to transmit and, in some cases, affect or even distort reality.

From a linguist's perspective, then, language is a highly structured system, and this structure is important for understanding how language can be used so readily and efficiently. However, it cannot be the structure of language alone that makes it such a useful tool, for if that were the case it would be difficult to understand why humans alone come to have fully developed language skills. Rather, it must be the structure of language in combination with that of the human brain that explains how humans acquire, use, and create language. A question then arises: Does the human brain "see" language the way that linguists see language?

As just discussed, linguists have uncovered language patterns at various levelsphonological, morphological, syntactic, semantic, pragmatic. Cognitive neuroscientists and psycholinguists have long sought to determine whether these regularities arise from some aspect of sensory and cognitive processing. It seems likely that at 
least some of these distinctions are also important to the brain. At some level, for example, the brain probably does process phonological patterns differently from semantic or syntactic ones, and there is likely to be some difference between the brain's processing of two different sounds that are ultimately treated alike and two that are ultimately distinguished. However, linguists have typically focused on general principles of language organization and function that cut across individual languages, across individual language speakers, and even across individual instances of language performance. In other words, they are generally not concerned with processing issues and thus often examine patterns collapsed across time and space. However, the brain's processing of language necessarily takes place in time and space, and brain scientists are dedicated to delineating the importance of both. For example, linguistic inputs that are separated by different stretches of time (e.g., different numbers of words) or that require different numbers/sizes of saccadic eye movements are liable to be treated differently by the brain, though not, perhaps, by linguists. At the same time, not all differences noted by linguists are likely to be meaningful to all brain areas at all times. Early in visual processing, for instance, the brain responds similarly to letter strings that can be pronounced (i.e., are phonologically legal) and those that cannot.

Clearly then, any processing account of language must reconcile the categories that linguists have inferred from analysis of the world's languages (competence) with the processes that brain scientists have inferred from various neurobiological measures of brain activity during language performance; thus cognitive neuroscientists and psycholinguists have long been interested in the brain's "view." However, the issue of whether the brain sees language as linguists do (and why the answer should matter) has been of some debate among linguists. To a large extent, the debate has played out along the lines of functionalist versus reductionist views of the study of mind (Churchland, 1984; Fodor, 1981). The strongest functionalist stance on this issue came from Noam Chomsky. With a pronounced emphasis on mental phenomena over and above mere observable linguistic behavior, Chomsky firmly established modern linguistic science as practiced in the latter half of the twentieth century as a functionalist enterprise par excellence:

Mentalistic linguistics is simply theoretical linguistics that uses performance as data (along with other data, for example, the data provided by introspection) for the determination of competence, the latter being taken as the primary object of its investigation. The mentalist, in this traditional sense, need make no assumptions about the possible physiological basis for the mental reality that he studies. In particular, he need not deny that there is such a basis. One would guess, rather, that it is the mentalistic studies that will ultimately be of greatest value for the investigation of neurophysiological mechanisms, since they alone are concerned with determining abstractly the properties that such mechanisms must exhibit and the functions they must perform. [Chomsky, 1965, p. 193, fn. 1]

From this point of view we can proceed to approach the study of the human mind much in the way that we study the physical structure of the body. In fact, we may think of the study of mental faculties as actually being a study of the body-specifically the brain-conducted at a certain level of abstraction. [Chomsky, 1980, p. 2]

In essence, Chomsky's original answer to this question was that ultimately, the brain would indeed have to see language the way the linguist does, because only the linguist is in a position to determine the primitives and operations in need of neural implementation. Chomsky later modified this position by acknowledging that primary linguistic data provided by introspection were no longer able to decide among competing linguistic theories, and that linguists would therefore need to take into consideration other sources of evi- 
dence derived from performance measures, including neural imaging data.

At the opposite extreme, perhaps the strongest reductionist answer to the question of the appropriate characterization of the brain-language relationship came from a structural linguist, Charles Hockett:

\footnotetext{
The essential difference between the [analytical] process in the child and the procedure of the linguist is this: the linguist has to make his analysis overtly, in communicable form, in the shape of a set of statements which can be understood by any properly trained person, who in turn can predict utterances not yet observed with the same degree of accuracy as can the original analyst. The child's 'analysis' consists, on the other hand, of a mass of varying synaptic potentials in his central nervous system. The child in time comes to behave the language; the linguist must come to state it... . [The linguistic scientist's] purpose in analyzing a language is not to create structure, but to determine the structure actually created by the speakers of the language. For the scientist, then, 'linguistic structure' refers to something existing quite independently of the activities of the analyst: a language is what it is, it has the structure it has, whether studied and analyzed by a linguist or not. [Hockett, 1963, p. 280]
}

Although this was originally published in 1948 and reflects the behaviorism of the time, it nonetheless seems not all that far removed from a present-day neoempirist position on this issue.

Nowadays, both psychological functionalists and reductionists are interested in how the brain "sees" language. For example, one of the characteristics that Fodor (1983) assigns to mental modules is association with fixed neural architecture. In part because of this, much of the current interest in neural imaging techniques among linguists and psycholinguists comes from those with functionalist leanings. Thus, taking the brain's perspective on language will likely yield useful data for scientists of any theoretical persuasion, and that is what we will attempt to do here.

\section{METHODS FOR EXAMINING BRAIN FUNCTION}

The brain not only represents language but also is involved in its creation and its real-time use. To understand how requires knowing something about the brain and about what regularities in language the brain notices and under what circumstances. Thus, cognitive neuroscientists interested in language processing have turned to a number of noninvasive brain imaging techniques in order to get various mutually constraining pictures of the brain in action as it processes language. These include direct measures of brain electrical activity and measures of metabolic processes that support such activity.

Comprehending and producing language are brain functions that require the coordinated activity of large groups of neurons. This neural communication is electrochemical in nature, involving the movement of electrically charged elements known as ions. Under normal (nonstimulated) conditions, each neuron has a "resting" electrical potential that arises due to the distribution of ions inside and outside it. Stimulation of the neuron changes the permeability of the neural membrane to these charged elements, thereby altering the electrical potential. A transient increase in potential (depolarization) at the cell body can cause an all-ornone wave of depolarization that moves along the cell's axon, known as an "action potential." The action potential then spreads to other neurons via the release of neurotransmitters from the axon terminals; these neurotransmitters diffuse across extracellular space (synaptic cleft) and cause permeability changes in the dendrites of nearby neurons. These permeability changes may cause an action potential in the receiving cell as well, or may simply alter the electrical potential of that cell such that it will be more or less sensitive to ensuing stimulation. 
Neural communication thus involves wavelike changes in the electrical potential along neurons and their processes. These current flows are the basis for electrophysiological recordings in the brain and at the scalp surface, because changes in electrical potential can be monitored by placing at least two electrodes somewhere on the head (or in the brain) and measuring the voltage difference between them. The resulting electroencephalogram (EEG) observed at the scalp is due to the summed potentials of multiple neurons acting in concert. In fact, much of the observed activity at the scalp likely arises from cortical pyramidal cells whose organization and firing satisfy the constraints for an observable signal (for details, see, e.g., Allison, et al., 1986; Kutas and Dale, 1997; Nunez and Katznelson, 1981).

The EEG measures spontaneous, rhythmic brain activity occurring in multiple frequency bands. For the purposes of understanding the neural basis of language processing, however, cognitive neuroscientists are often interested in the brain's response to a particular event or kind of event, such as the appearance of a word on a computer screen. To examine eventrelated activity in particular, one can average the EEG signal time-locked to the stimuli of interest to create an "eventrelated potential" or ERP. The ERP is a wave form consisting of voltage fluctuations in time, one wave form for each recording site. This wave form consists of a series of positive- and negative-going voltage deflections (relative to some base line activity prior to event onset). Under different experimental conditions, one can observe changes in wave form morphology (e.g., presence or absence of certain peaks), the latency, duration, or amplitude (size) of one or more peaks, or their distribution over the scalp. Until recently, electrophysiological investigations of language have focused on relatively fast (high-frequency), transient ERP responses; more recently, however, slower potentials that develop over the course of clauses and sentences have also been monitored.

ERPs are informative indices of language-related processes because they are a continuous, multidimensional signal. Specifically, ERPs provide a direct estimate of what a significant part of the brain is doing just before, during, and after an event of interest, even if it is extended in time. And, they do so with millisecond resolution. ERPs can indicate not only that two conditions are different, but also how-whether, for example, there is a quantitative change in the timing or size of a process or a qualitative change in the nature of processing or involvement of different brain generators as reflected in a different morphology or scalp distribution. To a limited extent, ERPs can also be used to infer where in the brain processes take place [via source modeling techniques and in combination with other neuroimaging techniques; for more information see Dale and Halgren (2001) and Kutas et al., (1999)].

Because it is difficult to localize precisely the neural source of electrical signals recorded at the scalp from the electrical recordings alone, other types of brain imaging methods have been brought to bear on attempts to link specific brain areas with cognitive processes. The brain requires a constant supply of blood to meet its metabolic demands, which in turn change with neural activity. With increased neuronal activity, glucose consumption goes up and there are concomitant local increases in blood flow and changes in oxygen extraction from the blood. These hemodynamic (and metabolic) changes can be monitored with techniques such as positron emission tomography (PET) and functional magnetic resonance imaging (fMRI). Local changes in blood flow during a cognitive task, for example, can be followed with PET using ${ }^{15} \mathrm{O}$-labeled water. Because these increases in blood flow exceed increases in local oxygen extraction, blood near regions of neural 
activity eventually has higher concentrations of oxygenated hemoglobin compared to blood near inactive regions. Such differences can be measured with fMRI, because as hemoglobin becomes deoxygenated it becomes more paramagnetic than the surrounding tissue, thereby creating a magnetically inhomogeneous environment. Under the right circumstances, these hemodynamic imaging methods can localize regions of neural activity with high spatial resolution. Their temporal resolution, however, is poorer, because hemodynamic responses typically lag the electrical signal by $1-2 \mathrm{sec}$ and do not track activity on a millisecond-bymillisecond basis. Combinations of these measures of brain activity thus seem to offer the most complete picture of where, when, and how language is processed in the brain.

Using neuroimaging techniques, researchers have looked at language processing from early stages of word recognition through the processing of multisentence discourses, from the planning of a speech act to its articulation (e.g., Kutas and Van Petten, 1994; Osterhout, 1994; Osterhout and Holcomb, 1995). So doing reveals that the brain's processing of language involves many different kinds of operations taking place at different times and different temporal scales and in multiple brain areas. These operations differ in the extent to which they are general purpose versus language specific, in the extent to which they are affected by context (and to what types of contexts they are sensitive), and in the extent to which they interact with one another in space and time.

\section{LANGUAGE COMPREHENSION}

Initially, the brain cannot know whether an incoming stimulus is linguistic or not. Thus, its first task when confronted with a written, spoken, or signed word-as with any external, perceptual stimulus-is to determine what it is, or at least to what categories it might belong. This (unconscious) decision is crucial and difficult; in order to process a stimulus effectively, attention must be distributed over the stimulus appropriately, certain kinds of feature information must be extracted and possibly stored in memory, information needed to interpret the stimulus must be accessed from long-term memory, and so on. Because the brain cannot always know what kind of stimulus it will encounter at any given moment, some aspects of (especially early) perceptual processing are likely to be similar regardless of the nature of the stimulus. At times, processing decisions may also be guided by guesses-based on frequency, recency, and other predictive regularities gained from experience with the sensory world-about what the stimulus is likely to be. When it can, it seems that the brain makes use of both top-down (expectancy or contextbased) and bottom-up (stimulus-based) information to guide its analysis of input. Thus, if someone has been reading or listening to a stream of linguistic stimuli, their brain might be biased to treat incoming input as linguistic; in other contexts, the same input may initially be interpreted as nonlinguistic (e.g., Johnston and Chesney, 1974). To the extent that the context allows, the brain might also form expectations about the physical nature of the stimulus-color, size, font, loudness, voice, etc. Modulation of attention to such stimulus parameters is reflected in variations in the amplitude of early sensory ERP components that originate from primary and secondary sensoryprocessing areas in the brain (e.g., P1, N1, mismatch negativity, $\mathrm{Nd}$, processing negativity; see relevant chapters in this book). Depending on the task demands, there may also be various kinds of effects on later ERP components such as N2, P3, RP, etc., shown to vary systematically with cognitive variables.

\section{From Perception to Language}

Regardless of the nature or degree of available top-down information, however, 
the first task for successful language comprehension involves early sensory classification of the input. In the visual modality, for example, this might include differentiating single objectlike stimuli from strings, orthographically legal words from illegal words, or pseudowords from nonwords. Schendan and colleagues (1998) examined the time course of this type of classification by comparing the ERP responses to object like (real objects, pseudoobjects), wordlike (words, letter strings, pseudofont strings), and intermediate (icon strings) stimuli. Around 95 msec a negativity (N100) over midline occipital sites distinguished single objectlike stimuli from strings (see Fig. 1). This differentiation is important because, as supported by the neuropsychological literature, different attentional resources are required to process sets of spatially distinct objects as opposed to a single, spatially contiguous form, and these processes are mediated by different brain areas (e.g., Farah, 1990). This classification was followed shortly by a distinction between strings made from real letters (words and pseudowords) and those made from other characters (icon strings, pseudofont), suggesting that the visual system of experienced readers has developed the ability rapidly to detect physical stimuli with the properties of real letters. Results from intracranial recording and fMRI studies suggest that such differentiations may be occurring in areas in the posterior fusiform gyrus (Allison et al., 1994) and the occipitotemporal and inferior occipital sulci (Puce et al., 1996). Finally, the ERPs showed a distinction between words and pseudowords, beginning approximately 200 msec poststimulus onset. Similar time courses of analyses and categorizations seem to hold for auditory inputs as well; for example, the ERPs to meaningful and nonsense words are very similar within the first $150 \mathrm{msec}$ of processing and begin to be distinguishable by $200-250 \mathrm{msec}$ (Novick et al., 1985).

Although ERPs provide a very temporally precise means of determining an upper limit on the time by which the brain must have appreciated the difference between two conditions or stimuli, they do not explicitly tell us either what that differ-

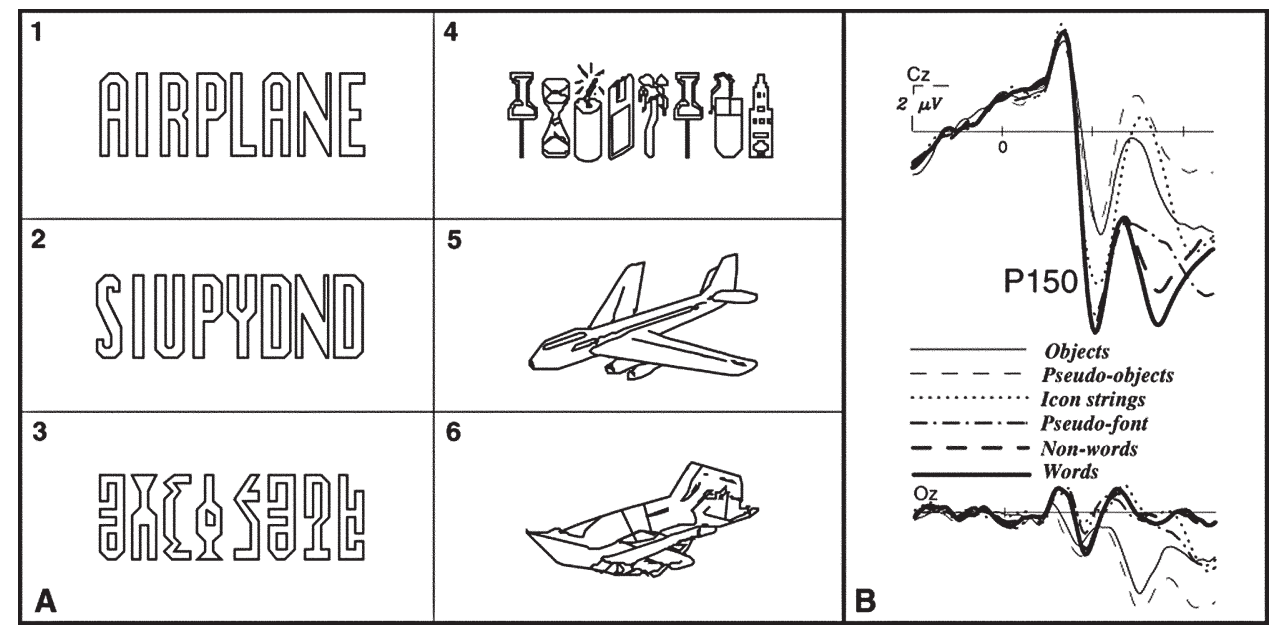

FIGURE 1 ERPs to visual stimuli. Sample stimuli (A) including (1) words, (2) nonwords, (3) pseudofont, (4) icon strings, (5) objects, (6) and pseudoobjects and the associated grand average ERPs (B) from a midline central $(\mathrm{Cz})$ and occipital $(\mathrm{Oz})$ electrode site. The P150 is large for stringlike stimuli (words, nonwords, and pseudofont), small for objectlike stimuli (objects and pseudoobjects), and intermediate for icon strings. From Schendan et al. (1998); reprinted with the permission of Cambridge University Press. 
ence means or the extent to which information about that difference will be available for or actually used in further processing. So, the fact that the processing of real words and pseudowords is differentiated at some level by $200-250 \mathrm{msec}$ does not necessarily mean that the brain has identified one type of stimulus as a word and the other as not a word (in the same way that a linguist or psycholinguist might). It may just reflect the brain's greater exposure to one class of stimuli than the other or its sensitivity to unusual (infrequent) letter combinations that characterize one class of stimuli more than the other. In fact, pronounceable pseudowords continue to be processed much like real words (in terms of the components elicited, though not necessarily in their size and latency) for several hundred milliseconds more. Unlike nonwords, but like stimuli bearing meaning, including real words, pronounceable pseudowords elicit a negativity peaking approximately $400 \mathrm{msec}$ poststimulus onset (N400). Thus, it would seem that at least some of the processing circuits of the brain deal with pseudowords, which have no particular learned meaning, no differently than these circuits do with real words for some time after an initial differentiation. Perhaps the early differentiation has less to do with whether any item is or is not a word and more to do with the extent of prior exposure. ERP research with children just acquiring language and/or reading skills as well as with adults learning a second language may provide a means for examining this hypothesis (Mills et al., 1997; Neville et al., 1997; Weber-Fox and Neville, 1996). Indeed, answering such questions poses one of the major challenges in cognitive neurolinguistics.

It is around the time that the brain's response to words seems to first diverge from that to pseudowords that the ERP also first shows a sensitivity to a word's frequency of occurrence in a given language (Francis and Kucera, 1982)—or, from the brain's point of view, the context-independent probability of encountering a particular word. King and Kutas (1998b) found that the latency of a left anterior negativity (which they labeled the lexical processing negativity, or LPN) occurring between 200 and $400 \mathrm{msec}$ poststimulus onset is strongly correlated with a word's frequency of occurrence in the language (see Fig. 2). In short, the brain seems to process more rapidly words that it has had more experience processing. This kind of early difference in the speed with which words are processed can have large consequences later in the processing stream.

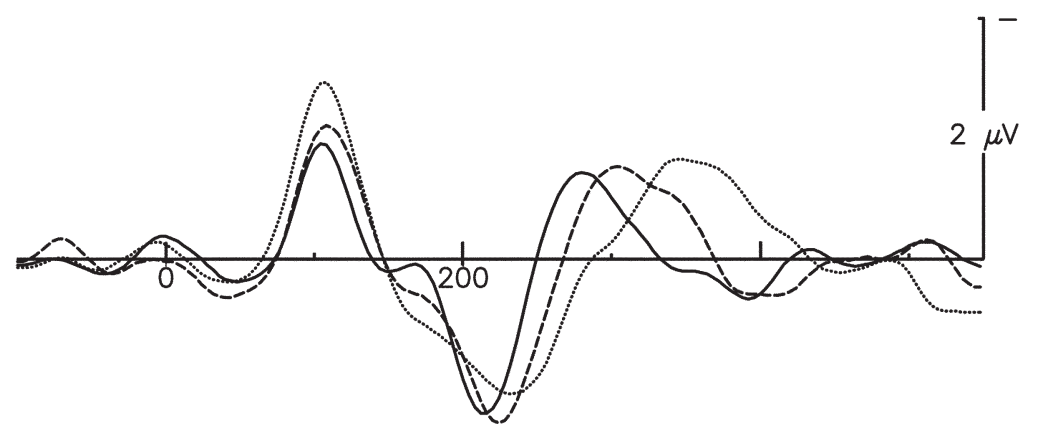

FIGURE 2 The lexical processing negativity is sensitive to word frequency. Grand average ERPs in response to words presented one at a time in sentences read for comprehension. Overlapped are the ERPs (digitally high-pass filtered at $4 \mathrm{~Hz}$ ) to words sorted as a function of their frequency of occurrence in the English language. The latency of the negative peak is longest $(\sim 340 \mathrm{msec})$ for low-frequency $(\cdots .$.$) and shortest (\sim 280 \mathrm{msec})$ for highfrequency (--) words. Medium-frequency (----) words peak at $300 \mathrm{msec}$. Data from King and Kutas (1998b). 
King and Kutas (1998b) suggested that at least some of the reported differences between the processing of "open class" (nouns, verbs, adjectives, adverbs) and "closed class" (determiners, articles, prepositions) words were due to differences in their average frequency and the consequences this had on their early neural processing (also see Brown et al., 1999; Münte et al., 2001; Osterhout et al., 1997a).

It is important to point out, however, that there is no single time or place where "word frequency" is processed and/or stored. Rather, word frequency affects multiple stages of processing, including word identification, access of associated phonological or semantic information from longterm memory, maintenance of word form or associated information in working memory, etc. In fact, ERP results clearly demonstrate that word frequency has different effects later in a word's processing. For example, with all other factors held constant (especially in the absence of semantic context), N400 amplitude is an inverse function of word frequency (Van Petten and Kutas, 1991). As will be discussed later, the N400 seems to be related to the access of semantic information from long-term memory and/or the integration of this information into a larger context. This aspect of processing is also affected by more "immediate" or local frequency information-namely, repetition in the experimental context (e.g., Rugg, 1985). Similar to the effects of global frequency information, repetition reduces the amplitude of the N400 activity, among the effects it has on other components (Van Petten et al., 1991).

\section{Processing Patterns}

The fact that a word is encountered frequently or was just encountered thus affects the way it is processed by the brain. Moreover, it affects the processing at different times and most likely in different ways: the time interval since the last repetition, the number of repetitions, and the context within which the repetition occurs all seem to matter, albeit differently as a function of the individual's age (Besson and Kutas, 1993; Besson et al., 1992; Kazmerski and Friedman, 1997; Nagy and Rugg, 1989; Rugg et al., 1997; Young and Rugg, 1992). More specifically, words repeated in the context of a word list are typically characterized by an enhanced positivity; the effects of repetition overlap but are not limited to the region of the N400 and are thought to comprise multiple components. Repetition effects are large on immediate repetition (with no delay lag) in young and older adults. At longer lags, the pattern of effects is more variable in general and apparently smaller, if present at all, in older individuals. Although multiple repetitions of a word progressively diminish the amplitude of the N400 component, this reduction is modulated by the nature of the context in which the word reappears; a word repeated in an altered context seems to show little signs of N400 reduction (Besson and Kutas, 1993). However, when a word is repeated in the same context, its N400 amplitude is progressively reduced by repetition, even if it is semantically anomalous within its context, such that by a third presentation, the N400 region is characterized by a large posterior positive component. In fact, the repetition effect is more pronounced for semantically anomalous than for semantically congruous sentence endings.

Effects like these are likely to hold for language units larger than words as welle.g., frequent and infrequent word combinations and frequent or infrequent syntactic structures. Indeed, ERPs reveal the importance of probability in the brain's processing of syntactic aspects of a sentence. A late positivity, variously called the P600 or "syntactic positive shift" (SPS), has most commonly been elicited in response to dispreferred, low-frequency, but possible continuations of sentences, as well as to outright syntactic violations (e.g., Coulson et al., 1998b; Hagoort et al., 1993; Neville 

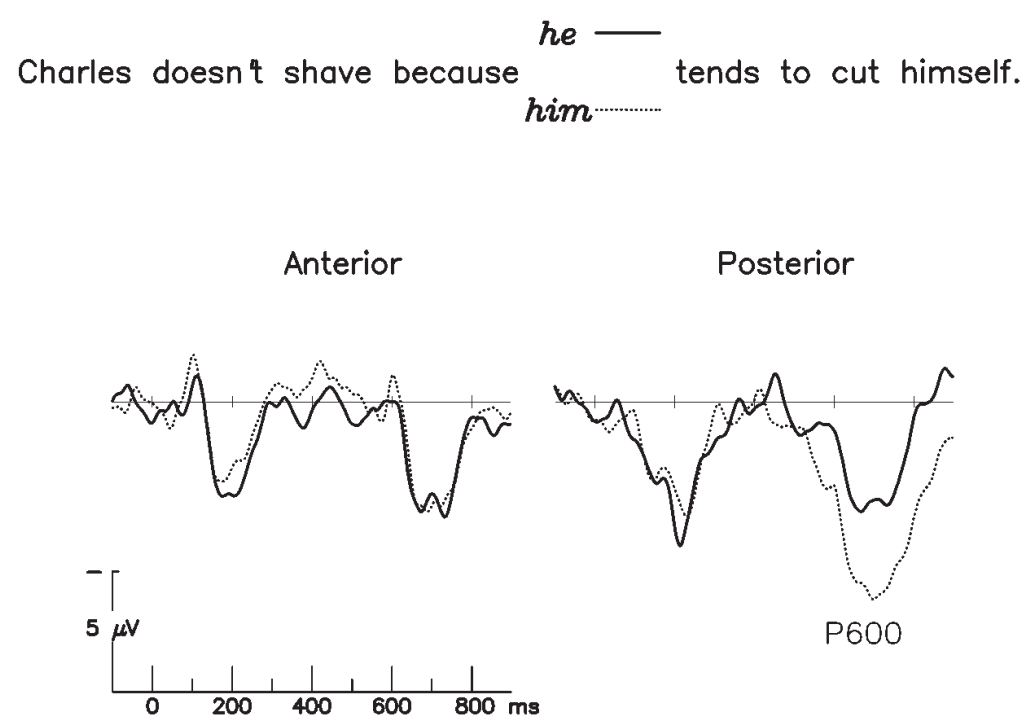

FIGURE 3 The P600. Grand average ERPs to target words in grammatical (solid) and ungrammatical (dotted) sentences at one anterior (left) and one posterior (right) electrode site. Compared to grammatical controls, ERPs to ungrammatical stimuli (here, case violations) are associated with enhanced positivity between 600 and 800 msec over posterior scalp sites.

et al., 1991; Osterhout and Holcomb, 1992). This positivity has a variable onset latency (generally late, but sometimes as early as $200 \mathrm{msec}$, depending on stimulus onset asynchrony) and a midpoint around $600 \mathrm{msec}$ - though this may vary with the complexity of the linguistic structure involved (Münte et al., 1997b). Its scalp distribution is most often posterior, though anterior effects have also been reported (see Fig. 3).

The P600 is typically observed when some aspect of a sentence violates structural (as opposed to semantic) expectations. For example, the P600 is reliably elicited when low-level morphosyntactic violations occur in a sentence, as when a subject does not agree in number with its verb ("Every Monday he mow the lawn"), when a noun phrase is incorrectly marked for case ("Ray fell down and skinned he knee") or number ("It has a nasty tempers and bites"), or when the second verb of a compound form is incorrectly inflected ("Dew does not fell like rain does"). In addition, late positivity is also seen in the
ERP response when the expected canonical word order of a phrase is disrupted ("Max's of proof the theorem") or when a verb's argument structure requirements are not met ("The broker persuaded to sell the stock"). It is important to note, however, that the P600 is not contingent on the presence of a grammatical violation; it is also elicited by points of processing difficulty, when the difficulty stems from processing at a grammatical or structural level (Kaan et al., 2000; Osterhout and Holcomb, 1992). Although these manipulations are all "syntactic" to linguists, they differ significantly from one another in ways that are likely to matter to the brain. For example, some, such as word order violations, depend almost exclusively on position in the linear string, whereas others, such as morphosyntactic violations, depend instead on the relationship between words in a sentence, relatively independent of their linear sentence position. Still others, such as verb argument structure violations, depend not only on the relationship between sentence elements, but also on the relationship of 
those sentence elements to requirements specified in the lexical entry of the verb.

So what might the P600 be indexing? A clue comes from work by Coulson and colleagues (1998b), who examined the response to morphosyntactic violations of subject-verb agreement and case marking when these violations were either frequent or infrequent in an experimental run. They observed a P600 response to ungrammatical as compared with grammatical trials, although infrequent ungrammatical events elicited larger P600s than did frequently occurring ungrammatical events. Moreover, even grammatical events elicited some P600 activity when they occurred infrequently among many ungrammatical sentences (for further discussion see Coulson et al., 1998a; Gunter et al., 1997; Münte et al., 1998a; Osterhout and Hagoort, 1999; Osterhout et al., 1996).

It seems, then, that the part of the brain that is sensitive to syntactic violations is also sensitive to the subjective probability of those violations. Although the P600 is not typically elicited by semantically improbable events, it can be elicited subsequent to N400 effects in such contexts, and can even be elicited in response to nonstandard but orthographically and phonologically licit spellings of words (Münte et al., 1997b). This may suggest that, at least at some point, the processing of syntax takes place by reference to the relative (perceived?) frequency and reliability of various expected regularities in the language, a frequency that is continuously updated with experience. However, much work still remains to be done detailing the sensitivity of P600 amplitude to nonlinguistic variables, and understanding the nature of its relationship (identity, overlap, independence) from the group of positivities variously called the P3, P3b, P300, and late positive component, which likely encompass several distinct subcomponents.

The nature of early, sometimes left-lateralized frontal negativities that frequently precede the P600 in the ERPs to syntactic violations is somewhat less well understood. These negativities have been reported in two latency ranges: about 100 to $300 \mathrm{msec}$ postword onset, the early left anterior negativity (ELAN), and, more commonly, about 300 to 500 or $600 \mathrm{msec}$ postword onset, the left anterior negativity (LAN). These negativities have thus far eluded definitive identification as to their eliciting conditions, presumably because the experimental designs across studies have manipulated different variables and because, within individual studies, the manipulations undertaken have often been subject to more than one interpretation.

The left anterior negativity elicited between 300 and $600 \mathrm{msec}$ has basically been interpreted in one of two different ways. One is as a direct and immediate response to syntactic or morphosyntactic ill-formedness (e.g., Münte et al., 1993; Neville et al., 1991; Osterhout and Holcomb, 1992), and the other is as an index of working memory processes during sentence comprehension (Coulson et al., 1998b; King and Kutas, 1995; Kluender and Kutas, 1993). The problem in deciding between these two alternatives is that manipulations of syntactic wellformedness have often occurred in sentences that incorporate long-distance relationships, which tax working memory resources, and working memory manipulations of long-distance sentence relationships have often resulted in-or been confounded with-less than complete well-formedness, as measured by either grammaticality or acceptability. Moreover, there is additional evidence in support of both interpretations. In the case of morphosyntactic and word order violations, LAN effects have been dissociated from P600 effects when such violations occur in jabberwocky sentences containing pseudowords: in these cases, the P600 effects can be suppressed but the LAN effect persists (Canseco-Gonzalez et al., 1997; Münte et al., 1997a; but see also Hahne and Jescheniak, 
2001). This dissociation has been taken to mean that the LAN is the true marker of ill-formedness, whereas the P600 is merely an index of attempts on the part of the brain to recompute the sentence and make sense of the faulty input it is getting; this attempt at recomputation purportedly does not occur in jabberwocky sentences because no sense is to made of them in the first place. On the other hand, in support of the working memory interpretation, LAN effects have also been observed in tandem with P600 effects in response to long-distance, purely semantic violations of hyponymy that crucially range across two separate clauses (Shao and Neville, 1996). It may well be the case that both interpretations of the LAN are correct, i.e., that it is influenced both by syntactic illformedness and by working memory load (Kluender et al., 1998; Vos et al., 2001). Because both syntactic processing and verbal working memory are known functions of left frontal cortex, and because both tend to activate Broca's area in neural imaging studies (e.g., Dapretto and
Bookheimer, 1999; Embick et al., 2000; Kang et al., 1999; Ni et al., 2000), this could be one clear instance in which the brain is not strictly respecting linguistic analysis (see Fig. 4).

The early left anterior negativity elicited between 100 and $300 \mathrm{msec}$ postword onset is of slightly more recent vintage. The ELAN has most reliably been elicited in response to word category violations using auditory presentation (Friederici et al., 1993; Hahne and Friederici, 1999) and has been interpreted as an index of a first-stage syntactic parser sensitive only to word category (i.e., part of speech) information in building an initial phrase structure tree. Because of its early latency and variability, it has been highly controversial. The morphology of the component varies from study to study in an as yet unpredictable manner: sometimes it is part of a broad negativity extending throughout the entire epoch (Friederici et al., 1993, 1996), whereas at other times it is a phasic component with a clear peak (Hahne and Jescheniak, 2001). The relation of the ELAN to the

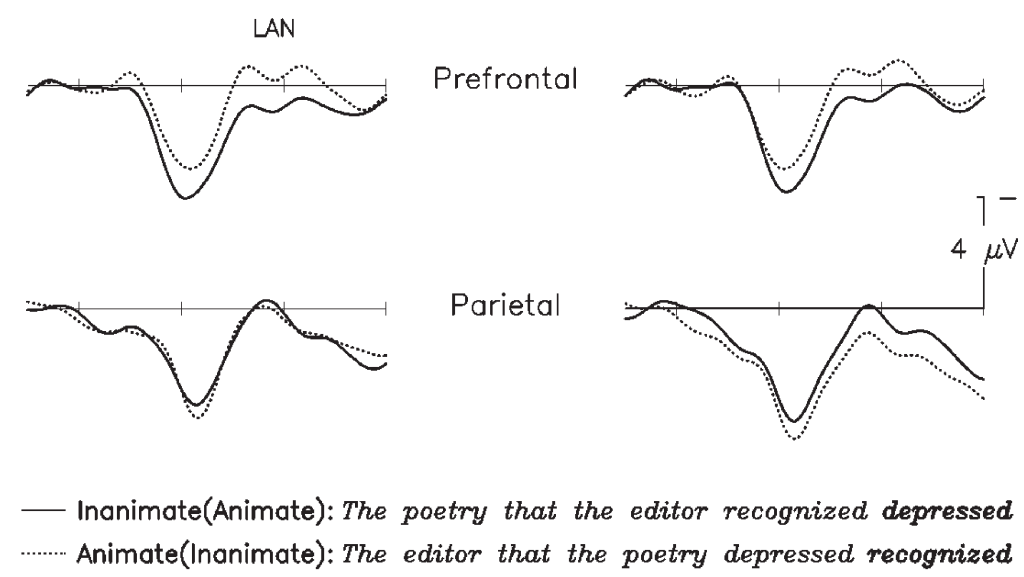

FIGURE 4 The left anterior negativity (LAN). Grand average ERPs to target sentence intermediate words (shown in bold type in the sentences) at left and right prefrontal (top) and left and right parietal (bottom) electrode sites. Responses at the main clause verb of object-relative sentences with an inanimate subject (solid lines) are compared with object-relative sentences with an animate subject (dotted lines). Animate subjects are harder to process in this construction because, although they tend to be subjects, they are here being used as objects of the relative-clause verb. In response to this increased ambiguity in syntactic processing, one observes increased negativity between 300 and $500 \mathrm{msec}$ over frontal sites, with a left-lateralized distribution (LAN). Over parietal sites, the beginning of a P600 response can also be observed. Data from Weckerly and Kutas (1999). 
LAN is also unclear. With low-contrast visual input, the latency of the component falls within that of the LAN (Gunter et al., 1999); in jabberwocky studies, very similar manipulations have resulted in ELAN effects in one case (Hahne and Jescheniak, 2001) and in LAN effects in another (Münte et al., 1997a); sometimes the ELAN is followed by a LAN, usually as a continuing negativity (Friederici et al., 1993, 1996; Hahne and Friederici, 1999), and sometimes it is not (Hahne and Friederici, 1999; Hahne and Jescheniak, 2001).

More generally, the relation of the anterior phasic negativities to the $\mathrm{P} 600$ is unclear-at times they precede it, at other times they do not. Is this due to an interaction with verbal working memory, activated in some cases more than others? Moreover, the relation of the anterior phasic negativities to the slow anterior negative potentials indexing verbal working memory load (as discussed in the next section) is equally unclear. These are issues that will need to be sorted out in future research. What such results do make clear, however, is that the brain is sensitive to the frequency and recency of exposure to particular patterns. Its sensitivities range from the probability of encountering a particular physical stimulus to the probability of those stimuli patterning in a particular way with respect to one another in a phrase or sentence.

\section{Working Memory}

The brain's sensitivity to linguistic patterns of various types highlights another important aspect of language, namely, the need to process relations between items, at different levels of abstraction. Many linguistic patterns emerge over the course of multiple words separated by time and/or space, depending on the modality of presentation. Processing relations between these items necessitates that the brain maintain them in some kind of temporary store or "working memory." Even simple, declarative sentences (e.g., "John really likes his pet $\left.\operatorname{dog}^{\prime \prime}\right)$ require working memory resources. At minimum, "John" must be held in memory so that the reader/listener knows who is being referred to when the pronoun "his" is encountered. Indeed, ERP data show that the brain is sensitive to the relationship between a pronoun and its antecedent. When an occupational title (e.g., "secretary") is paired with the more "probable" pronoun "she" (based on United States census data), less negativity is observed around 200 msec over left anterior sites than when the same occupation is paired with the less probable pronoun "he" (King and Kutas, 1998a). In the latter case, the brain may assume that the "he" refers to a new participant because the pronounantecendent pair seems less likely; the increased negativity may then reflect the working memory load associated with storing and/or holding onto information about two participants as opposed to only one. In a somewhat similar design with reflexive pronouns, Osterhout and coworkers (1997b) found that pronouns that disagreed with the gender definition or gender stereotype of an antecendent noun elicited a large positivity (i.e., the P600 typically associated with syntactic violations). The important point, however, is that pronouns elicit reliable ERP effects that can be used to investigate the link between them and the nouns to which they refer-a link that clearly relies on working memory.

Although all sentences tap into working memory, some clearly absorb more working memory resources than others (see Fig. 5). For instance, a sentence containing a relative clause (e.g., "The reporter who followed the senator admitted the error") typically requires more working memory resources than a simple declarative sentence, in part because a participant ("the reporter") is involved in two clauses/actions ("following" and "admitting"). These "subject-relative clauses," however, are presumed to require fewer 

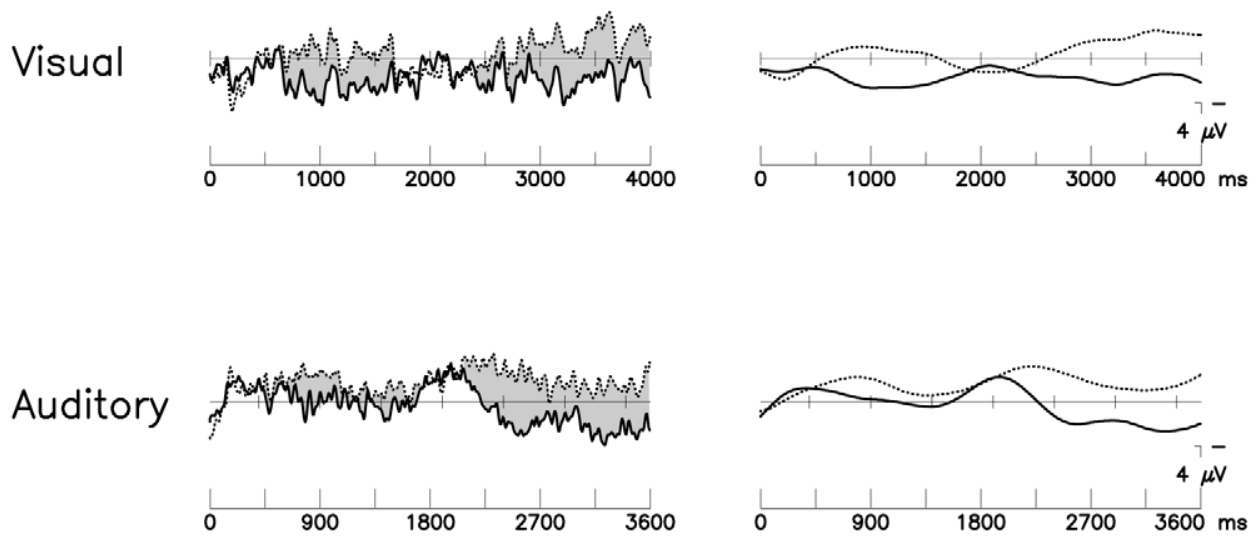

............. Object Relative: The reporter who the senator harshly attacked admitted the..

Subject Relative: The reporter who harshly attacked the senator admitted the..

FIGURE 5 Working memory and sentence processing. Comparison of grand average ERPs to subject-relative (solid lines) and object-relative (dotted lines) sentences from a left anterior site. On the left are the unfiltered data and on the right are the same data after they have been low-pass filtered to highlight slowly developing responses. The visual sentences were presented one word at a time, whereas the auditory sentences were presented as natural speech. The shading represents the area where object-relative sentences are reliably more negative than are subject-relative sentences. Visual data from Kutas and King (1996) and auditory data from Muller et al. (1997).

working memory resources than are objectrelative clauses, such as "The reporter who the senator followed admitted the error". In object-relative clauses, the subject of the main clause ("the reporter") must be kept distinct from the subject of the relative clause ("the senator"). By examining sentences that vary in the extent to which they require working memory resources, one can examine the nature of the brain's response to working memory load (e.g., Friederici et al., 1998; King and Kutas, 1995; Kutas and King, 1996; Mecklinger et al., 1995; Muller et al., 1997). In addition, one can assess individual variation in the brain's response to sentences of varying structural complexity as a function of the amount of working memory resources available (e.g., comparing individuals with high working memory "spans" with those who have fewer working memory resources). For example, King and Kutas (1995) compared ERP responses to subjectand object-relative sentences read one word at a time. As soon as the sentence structures varied, good comprehenders elicited greater left, frontal negativities in the object-relative as compared with the subject-relative clauses. This is the point in the sentence where, in the case of object relatives, a second participant ("the senator") must be stored in working memory (along with "the reporter"). In contrast, the response of poor comprehenders (with fewer working memory resources) was quite negative to both types of sentences; thus, both types of sentences seemed to tax working memory resources for poorer comprehenders. Similar effects were observed for these same sentences presented as natural speech (Muller et al., 1997). These results led to the hypothesis that the left anterior effect reflects general, as opposed to modality-specific, working memory operations. A similar left anterior negativity effect has also been observed for wh-questions (Kluender and Kutas, 1993). In English wh-questions (e.g., "Who did 
the doctor cure _?"), the wh-element (the "filler," in this case the word "who") appears at the beginning of the sentence, leaving a "gap" in the canonical word order (which in English is subject-verbobject). Another example comes from uncommon (and therefore difficult) word orders in German (Roesler et al., 1998). The role of working memory operations in sentence processing can also be examined by simply adding an irrelevant or elaborative clause to a simple transitive sentence (Gunter et al., 1995).

The extended nature of various working memory operations is also manifest in less transient, slow potential effects (longlasting potentials on the order of seconds). For example, in response to the subject versus object-relative clauses discussed above, good comprehenders show a slow positive shift to the subject-relative sentences over frontal sites that lasts for the duration of the relative clause and beyond; poor comprehenders do not show either this slow positivity or this difference (Kutas and King, 1996). This comprehension-related ERP difference shows up even for simple transitive sentences, with good comprehenders generating much more of a frontal positive shift compared to poorer comprehenders. At the same time, poorer comprehenders show enhanced early sensory visual components such as the $\mathrm{P} 1-\mathrm{N} 1-\mathrm{P} 2$ relative to the better comprehenders. This suggests that poorer comprehenders (as compared to good comprehenders) may have devoted more resources to lower level perceptual processing, thereby having fewer resources to devote to higher order (possibly workingmemory demanding) language processes. The potentials in normal elderly individuals for both simple transitive and objectrelative sentences most resemble those of the poorer comprehending younger individuals (Kutas and King, 1996).

A number of PET and fMRI studies also have compared subject-relative and objectrelative clauses, in the interest of localizing verbal working memory processes within the human brain. Because the left inferior frontal gyrus is a well-established language area commonly implicated in aspects of syntactic processing and production (i.e., Broca's area), it is perhaps not surprising that in all such studies to date, the left inferior frontal gyrus has emerged as a reliable locus of activation when the hemodynamic response to object-relative clauses has been compared to that for subject-relative clauses. This is also consistent with the finding that the neural circuitry for visuospatial working memory in the rhesus monkey involves extensive networks in prefrontal cortex (e.g., GoldmanRakic, 1990). Thus in an fMRI study, Just et al. (1996) compared center-embedded subject- and object-relative clauses like those above with active conjoined clauses (e.g., "The reporter followed the senator and admitted the error"), and found increased activation in both Broca's and Wernicke's areas for object-relative clauses compared to subject-relative clauses and for subject-relative clauses as compared to active conjoined clauses. On the other hand, a series of PET studies of centerembedded object relatives (e.g., "The juice [that the child spilled] stained the rug") vs. right-branching subject relatives (e.g., "The child spilled the juice [that stained the rug]") by Caplan and colleagues has consistently shown increased activation only in Broca's area, though the exact locus of activation within Broca's area has shifted slightly from study to study: the pars opercularis (Brodmann's area 44) in Stromswold et al. (1996) and Caplan et al. (1998), and the pars triangularis (Brodmann's area 45) in Caplan et al. (1999, 2000).

However, a Japanese fMRI study that manipulated center-embedded vs. leftbranching structures using only subjectrelative clauses in Japanese, a verb-final language, yielded a widespread increase in activation in response to the center-embedded subject relatives (Inui et al., 1998). This 
increase in activation appeared in both BA 44 and BA 45 of the left inferior frontal gyrus (i.e., Broca's area), as well as in the posterior portion of the left superior temporal gyrus (BA 22, i.e., Wernicke's area), and in left dorsolateral prefrontal cortex (the posterior part of BA 9). What is interesting about this comparison is that in order to maintain strict left branching in Japanese, the canonical subject-object-verb (SOV) word order of Japanese, preserved in the center-embedded condition, must be disrupted: the object noun plus its (preceding) relative clause must be moved to the front of the sentence, resulting in relatively rare OSV word order (corpus studies of both spoken and written Japanese text show that the OSV pattern occurs less than $1 \%$ of the time) (Yamashita, 2002). Note that this emulates the word order of object relatives in English ("...who the senator followed," "...that the child spilled," etc.). Thus at least in Japanese, center embedding with canonical word order seems to present a greater load for working memory than fronting an object in noncanonical word order. Naturally, more cross-linguistic studies of this nature are needed to tease apart conclusively the effects of center embedding, object fronting, basic word order, and neural imaging technique (PET vs. fMRI) in these working memory studies.

In general, neuroimaging results support claims originally made in the behavioral literature that successful language comprehension involves the storage and retrieval of information in working memory (e.g., Carpenter and Just, 1989; Daneman and Carpenter, 1980; Daneman and Merikle, 1996). Only through the use of working memory can the brain process critical relationships between sensory stimuli distributed over time and space. In addition, these results suggest that successful relational processing may call for more general, attentional resources. If more attention must be paid to lower level perceptual processes necessary for language comprehension, less attentional resources are available for the working memory operations especially critical for the processing of complex language structures.

\section{Long-Term Memory}

Although the processing of relations between items is crucial for successful language comprehension, at its heart language involves the processing of a different kind of relation-the relation between language elements and real-world knowledge stored in long-term memory (see McKoon and Ratcliff, 1998). Words are symbols-that is, they are associated with information that is not contained in the physical form of the word. It has been suggested that the human ability to remember, transform, and flexibly combine thousands of symbols is what especially sets us apart from other species (e.g., Deacon, 1997). Early in their processing, words are but perceptual objects with visual or acoustic properties that must be processed sufficiently to allow categorization and identification. Eventually, however, words serve as entry points into vast amounts of information stored in long-term memory. This associated information has been derived from many modalities (e.g., the shape and color of a carrot, its smell, its taste, its firmness, and smoothness; the crunching sound made when eating it) and has come to be associated with the word form through experience. The nature of the organization of long-term memory, the types of information that are stored, and the extent to which different information types are accessed under various conditions are all highly controversial issues.

Mirroring the concerns of psycholinguistics in general, many ERP investigations have been aimed at determining what kinds of information about words are typically retrieved during reading and listening and the time courses with which this information is retrieved. Moreover, given 
its unique ability to track word, sentence, and discourse-level processing with equal resolution, the ERP technique has also been directed at determining how information retrieved from the various words in a sentence is ultimately combined into a single message. ERP data suggest that the brain is clearly sensitive to some aspects of meaning by at least $250-300 \mathrm{msec}$ post stimulus onset. In this time window, the brain's response to words (and pronounceable pseudowords) in all modalities (spoken, printed, signed) (e.g., Holcomb and Neville, 1990; Kutas and Hillyard, 1980a, b; Kutas et al., 1987), to pictures (Ganis et al., 1996; Nigam et al., 1992) and faces (Barrett and Rugg, 1989; Bobes et al., 1994; Debruille et al., 1996), and to meaningful environmental sounds (Chao et al., 1995; Van Petten and Rheinfelder, 1995) contains a negativity with a posterior, slightly right hemisphere distribution at the scalp. Potentials at the same latency and sensitive to these same semantic variables are observed in the fusiform gyrus of patients with electrodes implanted for localizing seizure activity (e.g., McCarthy et al., 1995; Nobre and McCarthy, 1995); note that the polarity of a recorded potential depends on the location of the active electrode and reference, such that the intracranially recorded "N400s" are not always negative. This so-called N400 component was mentioned previously in the discussion of frequency and repetition effects, because its amplitude varies with both. In children and intact adults, the N400 seems to be the normal response to stimuli that are potentially meaningful. Some have suggested that the N400 reflects some kind of search through long-term, semantic memory; indeed N400 amplitude does vary with factors that also influence memory, such as the number of items to be remembered (Stuss et al., 1986) and the length of the delay between presentations of an item (e.g., Chao et al., 1995). Its amplitude is diminished and its latency is prolonged with normal aging, and even more so with various dementias (e.g., Iragui et al., 1993, 1996).

We have suggested that the N400 indexes some aspect of meaning because its amplitude is modulated by semantic aspects of a preceding context, be it a single word, a sentence, or a multisentence discourse. For instance, the amplitude of the N400 to a word in a list is reduced if that word is preceded by one with a similar meaning (e.g., N400 amplitude to "dog" is reduced when preceded by "cat" compared to "cup") (Brown and Hagoort, 1993; Holcomb and Neville, 1990; Van Petten et al., 1995). Brain activity in the same time region is also sensitive to phonological and orthographic relations between words (Barrett and Rugg, 1990; Polich et al., 1983; Praamstra et al., 1994; Rugg, 1984a; Rugg and Barrett, 1987). Similarly, the amplitude of the N400 to a word in a sentence is reduced to the extent that the word is compatible with the ongoing semantic context. An anomaly (e.g., "He takes his coffee with cream and dog") elicits the largest N400 response. Nonanomalous but less probable words (e.g., "He takes his coffee with cream and honey") generate less N400 activity than do anomalies but N400s of greater amplitude than more probable completions (e.g., "He takes his coffee with cream and sugar") (Kutas and Donchin, 1980; Kutas and Hillyard, 1980ab, 1984; Kutas et al., 1984). Discourse-level factors may also affect the magnitude of the N400 response. As single sentences, both "the mouse quickly went into its hole" and "the mouse slowly went into its hole" are congruous. However, in a larger discourse context (e.g., "Prowling under the kitchen table, the cat surprised a mouse eating crumbs. The mouse ... "), the two adverbs (quickly and slowly) are no longer equally expected; in fact, the N400 response to "slowly" in this type of context is larger than the response to "quickly" (van Berkum et al., 1999). Thus, at least around $400 \mathrm{msec}$, lexical, sentential, and discourse 
factors seem to converge to influence language comprehension and do so in a fairly similar manner. When both lexical and sentential factors are present, they seem to influence the N400 amplitude independently (Kutas, 1993; Van Petten, 1993, 1995; see also Fischler et al., 1985, for a similar conclusion). The relation of the N400 to semantic integrative processes is further supported by the observation that its amplitude is greatly attenuated and its latency is delayed in aphasic patients with moderate to severe comprehension problems, but not in patients with equivalent amounts of damage to the right hemisphere (Swaab et al., 1997).

The N400 is thus sensitive to the relationship between a word and its immediate sentential context and to that between a word and other words in the lexicon (see Fig. 6). Insofar as N400 indexes some aspect of search through memory, it seems then that the brain uses all the information it can as soon as it can to constrain its search. How does context serve to guide this search? We can think of information about word meaning as existing in a kind of space, structured by experience. The nature of this structure is often inferred
SEMANTIC CONGRUITY

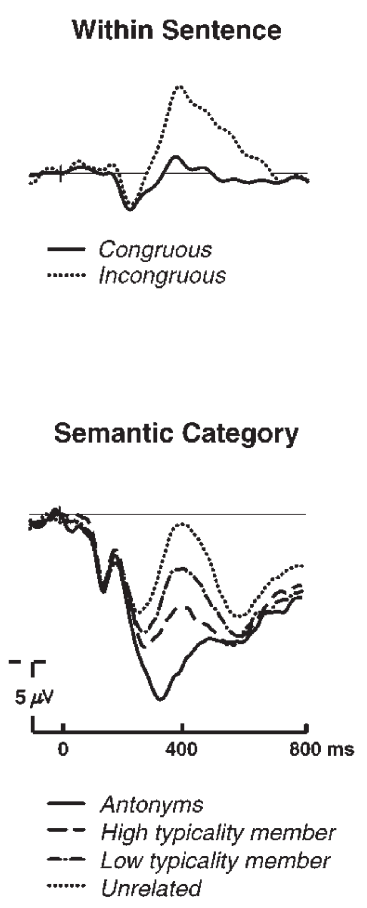

Sentence Final

Three Modalities

Written Word

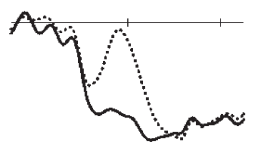

Spoken Word

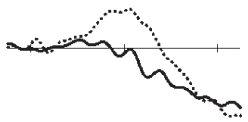

Line Drawing

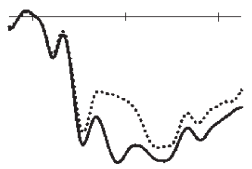

WORD REPETITION

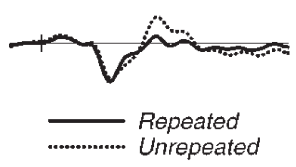

WORD FREQUENCY

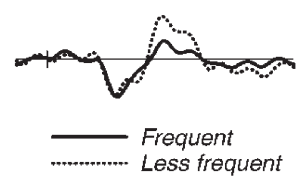

WORD POSITION

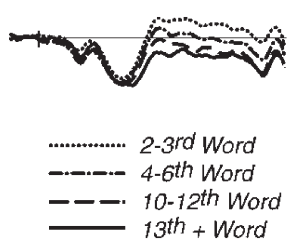

FIGURE 6 The N400 responses to various experimental manipulations, all shown here at a representative right posterior site. Incongruous words elicit large N400 amplitudes relative to congruous words, whether these items are in midsentence position (top left of figure) or in sentence final position. As shown in the center, this effect can be observed in all modalities, including written words, spoken words, and line drawings (here, all using the same experimental materials). As seen at bottom left, the N400 is similarly sensitive to varying degrees and types of semantic relations in more minimal contexts, including highly constrained antonyms (e.g., "The opposite of black ... white"; solid line), and category membership relations (e.g., "A type of bird ...) with high (e.g., "robin"; dashed line) or low (e.g., "turkey"; dot-dash line) typicality, as compared with unrelated items (dotted line). N400 amplitudes also vary with factors such as repetition, word frequency, and word position (see right side of figure). 
from the outcome of various categorization or sentence verification tasks (e.g., Kounios, 1996; Kounios and Holcomb, 1992; Kounios et al., 1994). Context (as well as the other factors known to influence N400 amplitude such as frequency or repetition) may serve to direct processing into different parts of this space-usually parts that render subsequent searches easier by bringing the processor into a state "closer" to the meaning of upcoming words. We have examined this hypothesis in a study in which participants were asked to read the following types of pairs of sentences:

Ann wanted to treat her foreign guests to an all-American dessert.

She went out in the back yard and picked some apples.

These sentence pairs were terminated with either the contextually expected item ("apples"), a contextually unexpected item that came from the same semantic category as the expected item (e.g., "oranges," another fruit), or an unexpected item from a different semantic category (e.g., "carrots"). Both types of unexpected endings elicited an N400 relative to congruent endings. However, even though both kinds of unexpected endings were equally inappropriate and implausible in the context, the unexpected item from the expected category elicited a smaller N400 than did the one from a different category. Moreover, the N400 reduction to such "within-category" violations was largest in highly constraining sentence contexts, where these violations were most implausible. The N400 does more than simply index the semantic fit between an item and its local context, therefore. Rather, this data pattern shows that the organization of sensory, motor, and higher order features in the brain built up of years of experience with the world (the fact that apples and oranges share more features in common than apples and carrots) has an inevitable impact on the neural processes (here seen in the N400 response) by which brains make sense of language in real time (Federmeier and Kutas, 1999b; Kutas and Federmeier, 2001).

An integral part of language comprehension, therefore, involves retrieving world knowledge associated with words and groups of words from long-term semantic memory. ERP data in conjunction with neuropsychological data and data from other neuroimaging techniques suggest that this meaning-related information resides in featural mosaics distributed across multiple brain areas, including higher order perceptual and motor-processing areas. fMRI studies (in accord with neuropsychological findings), for example, have shown that different brain areas become active in response to words (and/or pictures) representing different kinds of information (e.g., actions vs. colors) (Martin et al., 1995) and that patterns of activation within general brain areas, such as the ventral temporal cortex, vary as a function of semantic category as well (e.g., tools, animals) (see reviews by Humphreys et al., 1999; Martin and Chao, 2001). N400 data also reveal that the nature of the meaning information retrieved from long-term memory differs-even within the same linguistic context-for different types of stimuli (e.g., a picture vs. word representing the same concept) (Federmeier and Kutas, 2001) and as a function of which cerebral hemisphere preferentially (based on location of presentation) processes that information (Federmeier and Kutas, 1999a, 2002). The ERP data further suggest that meaning emerges from these distributed systems by virtue of temporally coincident and functionally similar activity within a number of brain areas [see also intracranial recording studies by Halgren et al. (1994a,b), McCarthy et al. (1995), and Nobre and McCarthy (1995)].

Language meaning thus emerges from an interaction between structure in the brain, built out of experience, and structure in the language stream. Context 
serves to shape not only the ease with which information can be found but also the nature of the information that is retrieved. Conceptual information also serves to shape language processing by providing a structure ("frame" or "schema") within which details beyond the level of individual words can be fit and related to one another. These "schemas" can be thought of as the brain's general expectations about the nature of information that will be retrieved and the order in which it will come. These schemas might well influence the extent to which various aspects of information are attended, how they are stored in working memory, and the ease with which they are comprehended. A study by Münte et al. (1998b) examined how people's schemas about time (built of daily experience) may affect the brain's processing of sentences and thus interact with working memory variables. People read sentences describing the temporal order of two events; the sentences differed only in whether their initial word was "before" or "after" (e.g., "Before/after the students took the exam the teacher called the parents"). Although these sentence types are otherwise identical in lexical content and syntactic structure, they differ in the extent to which they fit with our schema of time as a dimension moving from past to future. In "after" sentences, the two events are mentioned in accordance with this conception-the temporally earlier event coming first and the temporally later event coming second. By contrast, "before" sentences reverse this natural order. Münte et al. found that starting within $300 \mathrm{msec}$ of the initial word (the temporal term), "after" sentences showed a larger sustained positivity than did "before" sentences; this positivity was similar to that described for the relativeclause (object vs subject) contrast. This difference was, again, most pronounced for individuals with high working memory spans. The data suggest that our knowledge of the world (in this case, about time) has an immediate, lasting effect on processing, and that this impact is modulated by working memory capacity and/or availability. Words such as "before" and "after" serve as cues about the relationship between elements to come. These relations, in turn, are easier to process if they conform to general conceptual patterns derived from experience.

\section{CONCLUSIONS}

Comprehending language thus entails a number of different kinds of brain processes, including perceptual analysis, attention allocation, retrieval of information from long-term memory, storage of information in working memory, and comparisons between/transformations of information contained in working memory. These processes take place at multiple levels for different types of information (orthographic/phonological word form information, morphological/syntactic information, conceptual/semantic information) and unfold with different time courses; they are thus reflected in different electrophysiological processes with different time-courses, mediated by different brain areas.

Understanding language processing, therefore, demands that we apprehend how the multiple subprocesses involved interact over time and space. This, in turn, compels us to appreciate how the brain's processing of language interacts with more general processing demands. For example, both N400 and P600 amplitudes are responsive to attentional manipulations. The N400, for instance, is not observed when the priming context is masked (Brown and Hagoort, 1993), and N400 effects in word pair tasks are larger when the prime target interval is short and the proportion of related word pairs is high (Chwilla et al., 1995; Holcomb, 1988). Similarly, the P600 to verb inflection errors is greatly attenuated if not absent when 
people are asked to scan sentences merely to determine whether a word in a sentence is printed in upper case (Gunter and Friederici, 1999). Orthographic, phonological, morphological, syntactic, and pragmatic priming and context ERP effects seem to overlap temporally between 200 and 400 msec. Various and sundry memory-related and some attentionrelated ERP effects are observed in this very same interval. Moreover, the transient ERPs elicited during the analysis of a visual stimulus as a word are superimposed on the slower potentials that seem to be elicited during the processing of sentences and during various tasks requiring that information be retrieved from longer term memory. Indeed, the language specificity of any of these processes remains unknown to date.

What we do know is that language processing is a complex skill engaging the whole brain. The goal of electrophysiological investigations of language, as well as the goal of research exploring language processing with other tools, is to fashion an understanding of how the various processes involved in language comprehension and production are coordinated to yield the message-level apprehension we attain from reading or listening to speech. Linguists, psycholinguists, and neurolinguists alike strive to understand how the brain "sees" language-because, in turn, language is such an important facet of how humans "see" their world.

\section{References}

Allison, T., Wood, C. C., and McCarthy, G. (1986). The central nervous system. In "Psychophysiology: Systems, Processes, and Applications" (M. G. Coles, E. Donchin, and S. W. Porges, eds.), pp. 5-25. Guilford Press, New York

Allison, T., McCarthy, G., Nobre, A., Puce, A., and Belger, A. (1994). Human extrastriate visual cortex and the perception of faces, words, numbers, and colors. Cereb. Cortex 4(5), 544-554.

Barrett, S. E., and Rugg, M. D. (1989). Event-related potentials and the semantic matching of faces. Neuropsychologia 27(7), 913-922.
Barrett, S. E., and Rugg, M. D. (1990). Event-related potentials and the phonological matching of picture names. Brain Lang. 38(3), 424-437.

Besson, M., and Kutas, M. (1993). The many facets of repetition: A cued-recall and event-related potential analysis of repeating words in same versus different sentence contexts. J. Exp. Psycho.: Learning Memory Cogn. 19(5), 1115-1133.

Besson, M., Kutas, M., and Van Petten, C. (1992). An event-related potential (ERP) analysis of semantic congruity and repetition effects in sentences. J. Cogn. Neurosci. 4(2), 132-149.

Bobes, M. A., Valdes-Sosa, M., and Olivares, E. (1994) An ERP study of expectancy violation in face perception. Brain Cogn. 26(1), 1-22.

Brown, C., and Hagoort, P. (1993). The processing nature of the N400: Evidence from masked priming. J. Cogn. Neurosci. 5(1), 34-44.

Brown, C. M., Hagoort, P., and ter Keurs, M. (1999). Electrophysiological signatures of visual lexical processing: Open- and closed-class words. J. Cogn. Neurosci. 11(3), 261-281.

Canseco-Gonzalez, E., Love, T., Ahrens, K., Walenski, M., Swinney, D., and Neville, H. (1997). Processing of grammatical information in Jabberwocky sentences: An ERP study. Paper presented at the Cognitive Neuroscience Society, Fourth Annual Meeting, Boston, Massachusetts.

Caplan, D., Alpert, N., and Waters, G. (1998). Effects of syntactic structure and propositional number on patterns of regional cerebral blood flow. J. Cogn. Neurosci. 10(4), 541-552.

Caplan, D., Alpert, N., and Waters, G. (1999). PET studies of syntactic processing with auditory sentence presentation. Neuroimage 9(3), 343-351.

Caplan, D., Alpert, N., Waters, G., and Olivieri, A. (2000). Activation of Broca's area by syntactic processing under conditions of concurrent articulation. Human Brain Mapping 9(2), 65-71.

Carpenter, P. A., and Just, M. A. (1989). The role of working memory in language comprehension. In "Complex Information Processing: The Impact of Herbert A. Simon" D. Klahr and K. Kotovsky, eds.), pp. 31-68. Lawrence Erlbaum Assoc., Hillsdale, New Jersey.

Chao, L. L., Nielsen-Bohlman, L., and Knight, R. T. (1995). Auditory event-related potentials dissociate early and late memory processes. Electroencephalogr. Clin. Neurophysiol., 96(2), 157-168.

Chomsky, N. (1965). "Aspects of the Theory of Syntax." MIT Press, Cambridge, Massachusetts.

Chomsky, N. (1980). "Rules and representations. B. Blackwell, London.

Churchland, P. M. (1984). “Matter and Consciousness: A Contemporary Introduction to the Philosophy of Mind." MIT Press, Cambridge, Massachusetts. 
Chwilla, D. J., Brown, C. M., and Hagoort, P. (1995). The N400 as a function of the level of processing. Psychophysiology 32(3), 274-285.

Coulson, S., King, J. W., and Kutas, M. (1998a). ERPs and domain specificity: Beating a straw horse. Lang. Cogn. Processes 13, 653-672.

Coulson, S., King, J. W., and Kutas, M. (1998b). Expect the unexpected: Event-related brain response to morphosyntactic violations. Lang. Cogn. Processes 13(1), 21-58.

Dale, A. M., and Halgren, E. (2001). Spatiotemporal mapping of brain activity by integration of multiple imaging modalities. Curr. Opin. Neurobiol. 11(2), 202-208.

Daneman, M., and Carpenter, P. A. (1980). Individual differences in working memory and reading. J. Verbal Learn. Verbal Behav. 19(4), 450-466.

Daneman, M., and Merikle, P. M. (1996). Working memory and language comprehension: A metaanalysis. Psychonom. Bull. Rev. 3(4), 422-433.

Dapretto, M., and Bookheimer, S. Y. (1999). Form and content: Dissociating syntax and semantics in sentence comprehension. Neuron 24(2), 427-432.

Deacon, T. W. (1997). "The Symbolic Species." W. W. Norton, New York.

Debruille, J. B., Pineda, J., and Renault, B. (1996). N400-like potentials elicited by faces and knowledge inhibition. Cogn. Brain Res. 4(2), 133-144.

Embick, D., Marantz, A., Miyashita, Y., O'Neil, W., and Sakai, K. L. (2000). A syntactic specialization for Broca's area. Proc. Natl. Acad. Sci. U.S.A. 97(11), 6150-6154.

Farah, M. J. (1990). “Visual Agnosia: Disorders of Object Recognition and What They Tell Us about Normal Vision." MIT Press, Cambridge.

Federmeier, K. D., and Kutas, M. (1999a). Right words and left words: Electrophysiological evidence for hemispheric differences in meaning processing. Cogn. Brain Res. 8(3), 373-392.

Federmeier, K. D., and Kutas, M. (1999b). A rose by any other name: Long-term memory structure and sentence processing. J. Mem. Lang. 41(4), 469-495.

Federmeier, K. D., and Kutas, M. (2001). Meaning and modality: Influences of context, semantic memory organization, and perceptual predictability on picture processing. J. Exp. Psychol.: Learning Mem. Cogn. 27(1), 202-224.

Federmeier, K. D., and Kutas, M. (2002). Picture the difference: Electrophysiological investigations of picture processing in the cerebral hemispheres. Neuropsychologia 40, 730-747.

Fischler, I., Childers, D. G., Achariyapaopan, T., and Perry, N. W. (1985). Brain potentials during sentence verification: Automatic aspects of comprehension. Biol. Psychol. 21(2), 83-105.

Fodor, J. A. (1981). The mind-body problem. Sci. Am. 244(1), 114-123.
Fodor, J. A. (1983). "The Modularity of Mind: An Essay on Faculty Psychology." MIT Press, Cambridge, Massachusetts.

Francis, W. N., and Kucera, H. (1982). "Frequency Analysis of English Usage." Houghton Mifflin Company, Boston.

Friederici, A. D., Pfeifer, E., and Hahne, A. (1993). Event-related brain potentials during natural speech processing: Effects of semantic, morphological and syntactic violations. Cogn. Brain Res. 1(3), 183-192.

Friederici, A. D., Hahne, A., and Mecklinger, A. (1996). Temporal structure of syntactic parsing: Early and late event-related brain potential effects. J. Exp. Psychol.: Learning Memory Cogn. 22(5), 1219-1248.

Friederici, A. D., Steinhauer, K., Mecklinger, A., and Meyer, M. (1998). Working memory constraints on syntactic ambiguity resolution as revealed by electrical brain responses. Biol. Psychol. 47(3), 193-221.

Ganis, G., Kutas, M., and Sereno, M. I. (1996). The search for 'common sense': An electrophysiological study of the comprehension of words and pictures in reading. J. Cogn. Neurosci. 8, 89-106.

Goldman-Rakic, P. S. (1990). Cortical localization of working memory. In "Brain Organization and Memory: Cells, Systems, and Circuits" J. L. McGaugh and N. M. Weinberger et al., (eds.), pp. 285-298. Oxford University Press, New York.

Gunter, T. C., and Friederici, A. D. (1999). Concerning the automaticity of syntactic processing. Psychophysiology 36, 126-137.

Gunter, T. C., Jackson, J. L., and Mulder, G. (1995). Language, memory, and aging: An electrophysiological exploration of the N400 during reading of memory-demanding sentences. Psychophysiology 32(3), 215-229.

Gunter, T. C., Stowe, L. A., and Mulder, G. (1997). When syntax meets semantics. Psychophysiology 34(6), 660-676.

Gunter, T. C., Friederici, A. D., and Hahne, A. (1999). Brain responses during sentence reading: Visual input affects central processes. Neurorep.: Rapid Commun. Neurosci. Res. 10(15), 3175-3178.

Hagoort, P., Brown, C., and Groothusen, J. (1993). The syntactic positive shift (SPS) as an ERP measure of syntactic processing. Special Issue: Event-related brain potentials in the study of language. Lang. Cogn. Processes 8(4), 439-483.

Hahne, A., and Friederici, A. D. (1999). Electrophysiological evidence for two steps in syntactic analysis: Early automatic and late controlled processes. J. Cogn. Neurosci. 11(2), 194-205.

Hahne, A., and Jescheniak, J. D. (2001). What's left if the Jabberwock gets the semantics? An ERP investigation into semantic and syntactic processes during auditory sentence comprehension. $\operatorname{Cog} n$. Brain Res. 11(2), 199-212. 
Halgren, E., Baudena, P., Heit, G., Clarke, J. M., Marinkovic, K., Chauvel, P., and Clarke, M. (1994a). Spatio-temporal stages in face and word processing. 2. Depth-recorded potentials in the human frontal and Rolandic cortices [published erratum appears in J. Physiol. Paris 88(2) (1994), following p. 151]. J. Physiol. 88(1), 51-80.

Halgren, E., Baudena, P., Heit, G., Clarke, J. M., Marinkovic, K., and Clarke, M. (1994b). Spatiotemporal stages in face and word processing. I. Depth-recorded potentials in the human occipital, temporal and parietal lobes [corrected] [published erratum appears in J. Physiol. Paris 88(2) (1994), following p. 151]. J. Physiol. 88(1), 1-50.

Hockett, C. F. (1963). A note on structure. In "Readings in Linguistics" (M. Joos, ed.), pp. 279-280. American Council of Learned Societies, New York.

Holcomb, P. J. (1988). Automatic and attentional processing: An event-related brain potential analysis of semantic priming. Brain Lang. 35(1), 66-85.

Holcomb, P. J., and Neville, H. J. (1990). Auditory and visual semantic priming in lexical decision: A comparison using event-related brain potentials. Lang. Cogn. Processes 5(4), 281-312.

Humphreys, G. W., Price, C. J., and Riddoch, M. J. (1999). From objects to names: A cognitive neuroscience approach. Psychol. Res./Psychol. Forsch. 62(2-3), 118-130.

Inui, T., Otsu, Y., Tanaka, S., Okada, T., Nishizawa, S., and Konishi, J. (1998). A functional MRI analysis of comprehension processes of Japanese sentences. Neurorep.: Int. J. Rapid Commun. Res. Neurosci. 9(14), 3325-3328.

Iragui, V. J., Kutas, M., Mitchiner, M. R., and Hillyard, S. A. (1993). Effects of aging on event-related brain potentials and reaction times in an auditory oddball task. Psychophysiology 30(1), 10-22.

Iragui, V., Kutas, M., and Salmon, D. P. (1996). Eventrelated potentials during semantic categorization in normal aging and senile dementia of the Alzheimer's type. Electroencephalogr. Clin. Neurophysiol. 100, 392-406.

Johnston, V. S., and Chesney, G. L. (1974). Electrophysiological correlates of meaning. Science 186(4167), 944-946.

Just, M. A., Carpenter, P. A., Keller, T. A., Eddy, W. F., and Thulborn, K. R. (1996). Brain activation modulated by sentence comprehension. Science 274(5284), 114-116.

Kaan, E., Harris, A., Gibson, E., and Holcomb, P. (2000). The P600 as an index of syntactic integration difficulty. Lang. Cogn. Processes 15(2), 159-201.

Kang, A. M., Constable, R. T., Gore, J. C., and Avrutin, S. (1999). An event-related fMRI study of implicit phrase-level syntactic and semantic processing. Neuroimage 10(5), 555-561.

Kazmerski, V. A., and Friedman, D. (1997). Old/new differences in direct and indirect memory tests using pictures and words in within- and crossform conditions: Event-related potential and behavioral measures. Cogn. Brain Res. 5(4), 255-272.

King, J. W., and Kutas, M. (1995). Who did what and when? Using word- and clause-level ERPs to monitor working memory usage in reading. J. Cogn. Neurosci. 7(3), 376-395.

King, J. W., and Kutas, M. (1998a). He really is a nurse: ERPs and anaphoric coreference. Psychophysiology 35(Suppl. 1), S47.

King, J. W., and Kutas, M. (1998b). Neural plasticity in the dynamics of human visual word recognition. Neurosci. Lett. 244(2), 61-64.

Kluender, R., and Kutas, M. (1993). Bridging the gap: Evidence from ERPs on the processing of unbounded dependencies. J. Cogn. Neurosci. 5(2), 196-214.

Kluender, R., Münte, T., Cowles, H. W., Szentkuti, A., Walenski, M., and Wieringa, B. (1998). Brain potentials to English and German questions. J. Cogn. Neurosci. (Suppl.) 1, 24.

Kounios, J. (1996). On the continuity of thought and the representation of knowledge: Electrophysiological and behavioral time-course measures reveal levels of structure in semantic memory. Psychonom. Bull. Rev. 3(3), 265-286.

Kounios, J., and Holcomb, P. J. (1992). Structure and process in semantic memory: Evidence from event-related brain potentials and reaction times. J. Exp. Psychol. Gen. 121(4), 459-479.

Kounios, J., Montgomery, E. C., and Smith, R. W. (1994). Semantic memory and the granularity of semantic relations: Evidence from speed-accuracy decomposition. Memory Cogn. 22(6), 729-741.

Kutas, M. (1993). In the company of other words: Electrophysiological evidence for single-word and sentence context effects. Special Issue: Eventrelated brain potentials in the study of language. Lang. Cogn. Processes 8(4), 533-572.

Kutas, M., and Dale, A. (1997). Electrical and magnetic readings of mental functions. In "Cognitive Neuroscience" (M. D. Rugg, ed.), pp. 197-242. Psychology Press, Hove, East Sussex.

Kutas, M., and Donchin, E. (1980). Preparation to respond as manifested by movement-related brain potentials. Brain Res. 202(1), 95-115.

Kutas, M., and Federmeier, K. D. (2001). Electrophysiology reveals semantic memory use in language comprehension. Trends Cogn. Sci. 4(12), 463-470.

Kutas, M., and Hillyard, S. A. (1980a). Event-related brain potentials to semantically inappropriate and surprisingly large words. Biol. Psychol. 11(2), 99-116.

Kutas, M., and Hillyard, S. A. (1980b). Reading senseless sentences: Brain potentials reflect semantic incongruity. Science 207(4427), 203-205. 
Kutas, M., and Hillyard, S. A. (1984). Brain potentials during reading reflect word expectancy and semantic association. Nature 307(5947), 161-163.

Kutas, M., and King, J. W. (1996). The potentials for basic sentence processing: Differentiating integrative processes. In "Attention and Performance 16: Information Integration in Perception and Communication" (T. Inui and J. L. McClelland, eds.), pp. 501-546. MIT Press, Cambridge, Massachusetts.

Kutas, M., and Van Petten, C. K. (1994). Psycholinguistics electrified: Event-related brain potential investigations. In "Handbook of Psycholinguistics" (M. A. Gernsbacher, ed.), pp. 83-143. Academic Press, San Diego.

Kutas, M., Lindamood, T. E., and Hillyard, S. A. (1984). Word expectancy and event-related brain potentials during sentence processing. In "Preparatory States and Processes" (S. Kornblum and J. Requin, eds.), pp. 217-237. Lawrence Erlbaum Assoc., Hillsdale, New Jersey.

Kutas, M., Neville, H. J., and Holcomb, P. J. (1987). A preliminary comparison of the $\mathrm{N} 400$ response to semantic anomalies during reading, listening, and signing. Electroencephalogr. Clin. Neurophysiol. (Suppl.) 39, 325-330.

Kutas, M., Federmeier, K. D., and Sereno, M. I. (1999). Current approaches to mapping language in electromagnetic space. In "The Neurocognition of Language" (C. M. Brown and P. Hagoort, eds.), pp. 359-392. Oxford University Press, Oxford.

Maclay, H., and Osgood, C. E. (1959). Hesitation phenomena in spontaneous English speech. Word 15, 19-44.

Martin, A., and Chao, L. L. (2001). Semantic memory and the brain: Structure and processes. Curr. Opin. Neurobiol. 11(2), 194-201.

Martin, A., Haxby, J. V., Lalonde, F. M., and Wiggs, C. L. (1995). Discrete cortical regions associated with knowledge of color and knowledge of action. Science 270(5233), 102-105.

McCarthy, G., Nobre, A. C., Bentin, S., and Spencer, D. D. (1995). Language-related field potentials in the anterior-medial temporal lobe: I. Intracranial distribution and neural generators. J. Neurosci. 15(2), 1080-1089.

McKoon, G., and Ratcliff, R. (1998). Memory-based language processing: Psycholinguistic research in the 1990s. Annu. Rev. Psychol. 49, 25-42.

Mecklinger, A., Schriefers, H., Steinhauer, K., and Friederici, A. D. (1995). Processing relative clauses varying on syntactic and semantic dimensions: An analysis with event-related potentials. Memory Cogn. 23(4), 477-494.

Mills, D. L., Coffey-Corina, S., and Neville, H. J. (1997). Language comprehension and cerebral specialization from 13 to 20 months. Dev. Neuropsychol. 13(3), 397-445.

Muller, H. M., King, J. W., and Kutas, M. (1997). Event-related potentials elicited by spoken relative clauses. Cogn. Brain Res. 5(3), 193-203.

Münte, T. F., Heinze, H.-J., and Mangun, G. R. (1993). Dissociation of brain activity related to syntactic and semantic aspects of language. J. Cogn. Neurosci. 5(3), 335-344.

Münte, T. F., Matzke, M., and Johannes, S. (1997a). Brain activity associated with syntactic incongruencies in words and pseudo-words. J. Cogn. Neurosci. 9(3), 318-329.

Münte, T. F., Szentkuti, A., Wieringa, B. M., Matzke, M., and Johannes, S. (1997b). Human brain potentials to reading syntactic errors in sentences of different complexity. Neurosci. Lett. 235(3), 105-108.

Münte, T. F., Heinze, H. J., Matzke, M., Wieringa, B. M., and Johannes, S. (1998a). Brain potentials and syntactic violations revisited: No evidence for specificity of the syntactic positive shift. Neuropsychologia 36(3), 217-226.

Münte, T. F., Schiltz, K., and Kutas, M. (1998b). When temporal terms belie conceptual order: An electrophysiological analysis. Nature 395, 71-73.

Münte, T. F., Wieringa, B. M., Weyerts, H., Szentkuti, A., Matzke, M., and Johannes, S. (2001). Differences in brain potentials to open and closed class words: Class and frequency effects. Neuropsychologia 39(1), 91-102.

Nagy, M. E., and Rugg, M. D. (1989). Modulation of event-related potentials by word repetition: The effects of inter-item lag. Psychophysiology 26(4), 431-436.

Neville, H. J., Coffey, S. A., Lawson, D. S., Fischer, A., Emmorey, K., and Bellugi, U. (1997). Neural systems mediating American Sign Language: Effects of sensory experience and age of acquisition. Brain Lang. 57(3), 285-308.

Neville, H. J., Nicol, J. L., Barss, A., Forster, K. I., and Garrett, M. F. (1991). Syntactically based sentence processing classes: Evidence from eventrelated brain potentials. J. Cogn. Neurosci. 3(2), 151-165.

Ni, W., Constable, R. T., Mencl, W. E., Pugh, K. R., Fulbright, R. K., Shaywitz, S. E., Shaywitz, B. A., Gore, J. C., and Shankweiler, D. (2000). An eventrelated neuroimaging study distinguishing form and content in sentence processing. J. Cogn. Neurosci. 12(1), 120-133.

Nigam, A., Hoffman, J. E., and Simons, R. F. (1992). N400 to semantically anomalous pictures and words. J. Cogn. Neurosci. 4(1), 15-22.

Nobre, A. C., and McCarthy, G. (1995). Languagerelated field potentials in the anterior-medial temporal lobe: II. Effects of word type and semantic priming. J. Neurosci. 15(2), 1090-1098.

Novick, B., Lovrich, D., and Vaughan, H. G. (1985). Event-related potentials associated with the dis- 
crimination of acoustic and semantic aspects of speech. Neuropsychologia 23(1), 87-101.

Nunez, P. L., and Katznelson, R. D. (1981). "Electric Fields of the Brain: The Neurophysics of EEG." Oxford University Press, New York.

Osterhout, L. (1994). Event-related brain potentials as tools for comprehending language comprehension. In "Perspectives on sentence processing" (J. Charles Clifton, L. Frazier and K. Rayner, eds.), . pp. 15-44. Lawrence Erlbaum Assoc., Hillsdale, New Jersey.

Osterhout, L., and Hagoort, P. (1999). A superficial resemblance doesn't necessarily mean you're part of the family: Counterarguments to Coulson, King, and Kutas (1998) in the P600/SPS-P300 debate. Lang. Cogn. Processes 14, 1-14.

Osterhout, L., and Holcomb, P. J. (1992). Event-related brain potentials elicited by syntactic anomaly. J. Memory Lang. 31(6), 785-806.

Osterhout, L., and Holcomb, P. J. (1995). Event related potentials and language comprehension. In "Electrophysiology of Mind: Event-Related Brain Potentials and Cognition" (M. D. Rugg and M. G. H. Coles, eds.), Vol. 25, pp. 171-215. Oxford University Press, Oxford.

Osterhout, L., McKinnon, R., Bersick, M., and Corey, V. (1996). On the language specificity of the brain response to syntactic anomalies: Is the syntactic J. Cogn. Neurosci. 8(6), 507-526.

Osterhout, L., Bersick, M., and McKinnon, R. (1997a). Brain potentials elicited by words: Word length and frequency predict the latency of an early negativity. Biol. Psychol. 46(2), 143-168.

Osterhout, L., Bersick, M., and McLaughlin, J. (1997b). Brain potentials reflect violations of gender stereotypes. Memory Cogn. 25(3), 273-285.

Polich, J., McCarthy, G., Wang, W. S., and Donchin, E. (1983). When words collide: Orthographic and phonological interference during word processing. Biol. Psychol. 16(3-4), 155-180.

Praamstra, P., Meyer, A. S., and Levelt, W. J. M. (1994). Neurophysiological manifestations of phonological processing: Latency variations of a negative ERP component time-locked to phonological mismatch. J. Cogn. Neurosci. 6(3), 204-219.

Puce, A., Allison, T., Asgari, M., Gore, J. C., and McCarthy, G. (1996). Differential sensitivity of human visual cortex to faces, letterstrings, and textures: A functional magnetic resonance imaging study. J. Neurosci. 16(16), 5205-5215.

Roesler, F., Pechmann, T., Streb, J., Roeder, B., and Hennighausen, E. (1998). Parsing of sentences in a language with varying word order: Word-by-word variations of processing demands are revealed by event-related brain potentials. J. Memory Lang. 38(2), 150-176.

Rugg, M. D. (1984a). Event-related potentials and the phonological processing of words and nonwords. Neuropsychologia 22(4), 435-443.
Rugg, M. D. (1984b). Event-related potentials in phonological matching tasks. Brain Lang. 23(2), 225-240.

Rugg, M. D. (1985). The effects of semantic priming and word repetition on event-related potentials. Psychophysiology 22(6), 642-647.

Rugg, M. D., and Barrett, S. E. (1987). Event-related potentials and the interaction between orthographic and phonological information in a rhyme-judgment task. Brain Lang. 32(2), 336-361.

Rugg, M. D., Mark, R. E., Gilchrist, J., and Roberts, R. C. (1997). ERP repetition effects in indirect and direct tasks: Effects of age and interitem lag. Psychophysiology 34(5), 572-586.

Schendan, H. E., Ganis, G., and Kutas, M. (1998). Neurophysiological evidence for visual perceptual categorization of words and faces within $150 \mathrm{~ms}$. Psychophysiology 35(3), 240-251.

Shao, J., and Neville, H. (1996). ERPs elicited by semantic anomalies: Beyond the N400. Paper presented at the Cognitive Neuroscience Society, Third Annual Meeting, San Francisco, California.

Stromswold, K., Caplan, D., Alpert, N., and Rauch, S. (1996). Localization of syntactic comprehension by positron emission tomography. Brain Lang. 52(3), 452-473.

Stuss, D. T., Picton, T. W., and Cerri, A. M. (1986). Searching for the names of pictures: An eventrelated potential study. Psychophysiology 23(2), 215-223.

Swaab, T., Brown, C., and Hagoort, P. (1997). Spoken sentence comprehension in aphasia: Event-related potential evidence for a lexical integration deficit. J. Cogn. Neurosci. 9(1), 39-66.

van Berkum, J. J. A., Hagoort, P., and Brown, C. M (1999). Semantic integration in sentences and discourse: Evidence from the N400. J. Cogn. Neurosci. 11(6), 657-671.

Van Petten, C. (1993). A comparison of lexical and sentence-level context effects in event-related potentials. Special Issue: Event-related brain potentials in the study of language. Lang. Cogn. Processes 8(4), 485-531.

Van Petten, C. (1995). Words and sentences: Eventrelated brain potential measures. Psychophysiology 32(6), 511-525.

Van Petten, C., and Kutas, M. (1991). Influences of semantic and syntactic context in open- and closed-class words. Memory Cogn. 19(1), 95-112.

Van Petten, C., and Rheinfelder, H. (1995). Conceptual relationships between spoken words and environmental sounds: Event-related brain potential measures. Neuropsychologia 33(4), 485-508.

Van Petten, C., Kutas, M., Kluender, R., Mitchiner, M., and McIsaac, H. (1991). Fractionating the word repetition effect with event-related potentials. J. Cogn. Neurosci. 3(2), 131-150. 
Van Petten, C., Reiman, E., and Senkfor, A. (1995). PET and ERP measures of semantic and repetition priming. Poster, Soc. Psychophysiol. Res.

Vos, S. H., Gunter, T. C., Kolk, H. H. J., and Mulder, G. (2001). Working memory constraints on syntactic processing: An electrophysiological investigation. Psychophysiology 38(1), 41-63.

Weber-Fox, C., and Neville, H. J. (1996). Maturational constraints on functional specializations for language processing: ERP and behavioral evidence in bilingual speakers. J. Cogn. Neurosci. 8(3), 231-256.
Weckerly, J., and Kutas, M. (1999). An electrophysiological analysis of animacy effects in the processing of objective relative sentences. Psychophysiology 36(5), 559-570.

Yamashita, H. (2002). Scrambled sentences in Japanese. Linguistic properties and motivations for production (In press).

Young, M. P., and Rugg, M. D. (1992). Word frequency and multiple repetition as determinants of the modulation of event-related potentials in a semantic classification task. Psychophysiology 29(6), 664-676. 